\title{
The effects of vitamin D supplementation on adiponectin level and insulin resistance in first-degree relatives of subjects with type 2 diabetes: a randomized double-blinded controlled trial
}

Seyed Mohammad Mohammadi ${ }^{1}$, Seyed Ahmad Eghbali ${ }^{2}$, Sedighah Soheilikhah ${ }^{3}$, Saeedeh Jam Ashkezari ${ }^{4}$, Maryam Salami ${ }^{1}$, Mohammad Afkhami-Ardekani ${ }^{5}$, Arezoo Afkhami-Ardekani ${ }^{6}$

${ }^{1}$ MD, Endocrinologist, Assistant Professor, Department of Internal Medicine, Faculty of Medicine, Shahid Sadoughi University of medical sciences, Yazd, Iran

${ }^{2}$ MD, Internal Medicine Resident, Department of Internal Medicine, Faculty of Medicine, Shahid Sadoughi University of Medical Sciences, Yazd, Iran

${ }^{3}$ MD, Endocrinologist, Associate Professor, Department of Internal Medicine, Faculty of Medicine, Shahid Sadoughi University of medical sciences, Yazd, Iran

${ }^{4}$ Researcher, Diabetes Research Center, Shahid Sadoughi University of Medical Sciences, Yazd, Iran

${ }^{5}$ MD, Endocrinologist, Professor, Department of Internal Medicine, Faculty of Medicine, Shahid Sadoughi University of medical sciences, Yazd, Iran

${ }^{6}$ Medical Student, Faculty of Medicine, Tehran University of Medical Sciences. Tehran, Iran

\section{Type of article: Original}

\begin{abstract}
Background: Despite the certain role of both vitamin D and adiponectin in the regulation of insulin sensitivity, the interaction between these two agents has remained uncertain.

Objective: The present study aimed to determine whether vitamin D is able to change plasma adiponectin and affect glucose homeostasis and insulin sensitivity in first-degree relatives of subjects with type 2 diabetes.

Methods: This randomized clinical trial was conducted at Clinic of Shahid Sadoughi Hospital in Yazd, Iran, from January 25, 2012 to December 25, 2014. In this randomized, double-blinded controlled trial, 64 first-degree relatives of type 2 diabetic patients were assigned randomly to receive either vitamin D supplement (50000 IU vitamin $\mathrm{D}$ tablet weekly) plus lifestyle change as the intervention group $(\mathrm{n}=32)$ or placebo plus lifestyle change as the control group $(\mathrm{n}=32)$ for twelve weeks (three months).

Results: Fifty-three patients (28 in the intervention group and 25 in the control group) completed the study. Serum levels of vitamin D increased while insulin level and consequently insulin resistance (calculated by HOMA formula) significantly decreased in the case group (p-value $<0.001$ for all variables). Although the values of these three biomarkers showed a slight increase in control group, the changes were not statistically significant. The levels of the changes in other markers including adiponectin, Fasting Blood Sugar (FBS), triglyceride, and total cholesterol remained insignificant in both study groups after completing interventions compared with before interventions.

Conclusion: This study showed that decreased insulin resistance is expected by administrating vitamin D supplement in first-degree relatives of the patients with diabetes mellitus.

Trial Registration: The trial was registered at the Iranian Registry of Clinical Trials (http://www.irct.ir) with the IRCT ID: $201105176430 \mathrm{~N} 1$.

Funding: The authors received no financial support for the research or publication of this article.

Keywords: Vitamin D, Type 2 diabetes, Adiponectin, Insulin resistance, First degree relatives
\end{abstract}

\section{Corresponding author:}

Arezoo Afkhami-Ardekani, Medical Student, Faculty of Medicine, Tehran University of Medical Sciences. Tehran, Iran. Tell: +98.9131510803, E-mail: arz.afkhami@gmail.com

Received: November 09, 2015, Accepted: March 07, 2016, Published: September 2016

iThenticate screening: February 06, 2016, English editing: June 04, 2016, Quality control: August 04, 2016

(C) 2016 The Authors. This is an open access article under the terms of the Creative Commons Attribution-NonCommercialNoDerivs License, which permits use and distribution in any medium, provided the original work is properly cited, the use is non-commercial and no modifications or adaptations are made. 


\section{Introduction}

The main clinical characteristics in diabetes mellitus as a common health problem in almost all societies in the world is hyperglycemia resulting from disturbances in glucose metabolism processing as well as defects in insulin sensitivity. This phenomenon may lead to long-term damage and also failure in vital organs, such as the eyes, kidneys, cardiovascular system, and cerebrovascular system, and it even can be life-threatening (1). The two types of diabetes, i.e., types 1 and 2, have different pathophysiological fundamentals, i.e., autoimmune destruction of pancreatic islet beta cells leads to absolute insulin deficiency in type 1, whereas the main basis of type 2 is an increase of insulin resistance (2). Iran is one of the main areas where diabetes mellitus is prevalent in the world, and there has been an upward trend in the prevalence of diabetes due to the population's following unhealthy dietary regimens, decreasing their physical activity, and inappropriate lifestyles. The overall prevalence of diabetes is considerably higher in some provinces in Iran, such as Yazd, where the prevalence rate in individuals older than 18 who live in urban areas is estimated to be as high as $14.5 \%$ (3). Within the recent decade, it has been suggested that calcium and vitamin D have an essential role related to important metabolic cofactors in glucose metabolism and insulin production and secretion. Recently, it was demonstrated that 25 -hydroxy vitamin $\mathrm{D}$ is the main element to stimulate insulin secretion through its effect on Vitamin D receptors, which is expressed on insulin secreting cells in the pancreas (4). In this regard, vitamin D deficiency may increase the risk for insulin resistance and thus for developing diabetes mellitus and its related adverse events (5). Adiponectin is a $30 \mathrm{KDa}$ protein synthesized in adipocytes. The central role of adiponectin in regulating glycemic control, improving lipid profile metabolism, and also reducing inflammatory markers, especially in diabetic patients, has been well understood (6). In this regard, some studies have shown that reduced levels of adiponectin may play a role in increasing insulin resistance and developing type 2 diabetes mellitus $(7,8)$. Adiponectin deficiency also has been found to be a main precursor for developing diabetes in non-diabetic subjects (9). Soheilykhah et al. indicated that serum concentrations of adiponectin were significantly lower in gestational diabetes compared with patients with normal glucose tolerance (10). Despite the certain roles of both vitamin D and adiponectin in the regulation of insulin sensitivity, the interaction between these two agents has remained uncertain. Because of the importance of these interactions in both diabetic patients and their first-degree relatives, we aimed for the first time to determine whether vitamin D is able to change plasma adiponectin and affect glucose homeostasis and insulin sensitivity in first-degree relatives of subjects with type 2 diabetes.

\section{Material and Methods}

\subsection{Trial design}

This study was a randomized, double-blinded clinical trial that was conducted from January 25, 2012 to December $25,2014$.

\subsection{Participants}

This clinical trial was conducted in Clinic of Shahid Sadoughi Hospital (Shahid Sadoughi University of Medical Sciences) and its integrated Internal Medicine Department and Diabetes Research Center. The research population was comprised of first-degree relatives of patients with type 2 diabetes. In this randomized, double-blinded, controlled trial, 64 first-degree relatives of type 2 diabetic patients who were older than 25 and had body mass indices $\geq 25 \mathrm{Kg} / \mathrm{m}^{2}$ were included in the study.

\subsection{Selection criteria}

In this study, patients with FBS less than $126 \mathrm{mg} / \mathrm{dl}$ and 2 hour post prandial glucose (2hpp) less than $200 \mathrm{mg} / \mathrm{dl}$ were eligible for the study, and they were assigned randomly to receive either vitamin D supplement plus lifestyle change as the intervention group $(\mathrm{n}=32)$ or placebo plus lifestyle change as the control group $(\mathrm{n}=32)$. All of participants were first-degree relatives of people with type 2 diabetes. The exclusion criteria were history of administrating vitamin D or its supplements during the past three months as well as receiving metformin or any other drug that affects insulin resistance. The subjects were invited to come to the Yazd Diabetes Research Center after the study was announced in clinics, offices, and other healthcare centers. After obtaining written informed consent from all of the participants, blood samples were taken in order to measure the baseline serum biomarkers.

\subsection{Interventions}

The intervention subjects in the study were told to use one 50,000 IU vitamin D tablet weekly. During the threemonth period of study, patients were followed by phone or via Short Message Service (SMS) twice a week to remind them of the instructions. After three months, the patients returned to the Center so that we could reassess their serum biomarkers. Insulin resistance was calculated by the HOMA formula (HOMA= Fasting serum insulin 
$(\mu \mathrm{U} / \mathrm{ml}) \times$ Fasting blood sugar $(\mathrm{mmol} / \mathrm{l}) / 22.5)$. Cut-off level for vitamin $\mathrm{D}$ was $30 \mathrm{ng} / \mathrm{ml}$. Values greater than 30 $\mathrm{ng} / \mathrm{ml}$ were considered to be high. The specific kits that were used for detection of vitamin $\mathrm{D}$, adiponectin, and insulin by the Elisa method were 25 Hydroxy Vitamin D EIA kits from Immunodiagnostic System IDS Company, AviBion Human Adiponectin Eli A kit (Acro30) from Ani Biotech Oy Company and Diametra, respectively. A questionnaire was completed by the patients, including demographic data and test results. The rationale for lifestyle modifications was described and applied to both groups. All participants were informed about being at risk for diabetes mellitus, and they were encouraged to have regular exercise (fast walking for 30 minutes daily or swimming), to follow a diet that included the consumption of fresh fruits and vegetables and low-fat dairy products, as well as to avoid the use of excessive carbohydrates and to avoid consuming a high-fat diet.

\subsection{Outcomes}

In this study, before beginning the intervention, demographic parameters, age, and gender of the patients were recorded. Before the initiation of the intervention and 12 weeks afterwards, we recorded fasting blood sugar (FBS), 2hpp glucose, triglyceride, cholesterol, 25-hydroxy vitamin D, adiponectin, and fasting insulin level.

\subsection{Sample size}

According to relevant studies and by using of the sample size formula, $\mathrm{n}=\sigma^{2}\left(Z_{\alpha}+Z_{\beta}\right)^{2} / \mathrm{d}^{2}$, and assuming an alpha error of $5 \%$ and a study power of $80 \%$, the sample size was determined to be 32 subjects for each group.

\subsection{Randomization and blinding}

In this clinical trial, randomization was used with the baseline data of the patients. Randomization was done a staff member who did not have a role in the treatment of the participants. The randomization was done through SPSS 15 software (SPSS, Inc., Chicago, IL, USA). Also, the allocation was done by the researcher who was responsible for the randomization.

\subsection{Statistical methods}

Results were presented as mean \pm standard deviation (SD) for quantitative variables, and they were summarized by absolute frequencies and percentages for categorical variables. Categorical variables were compared using the chisquared test or Fisher's exact test when more than $20 \%$ of cells with an expected count of less than 5 were observed. Continuous variables were compared using one-way analysis of the t-test and/or the non-parametric Mann-Whitney test when the data did not appear to have a normal distribution. The change in study biomarkers after treatment protocols compared with baseline values was assessed using the paired t-test. The p-values of 0.05 or less were considered to be statistically significant. All of the statistical analyses were performed using SPSS version 15.0 for Windows (SPSS, Inc., Chicago, IL, USA).

\subsection{Research ethics}

The proposal for this thesis research was presented to the Ethics Committee of Shahid Sadoughi University of Medical Sciences and approved by the Internal Medicine Department. The Ethics Committee approved the study with the number P/17/1/50970 on December 23, 2010. The patients were informed about the objective and nature of the study, and each participant provided written consent prior to the study.

\section{Results}

Sixty-four patients were recruited for this study that received either vitamin D as the intervention group $(\mathrm{n}=32)$ or placebo as the control group $(\mathrm{n}=32)$. The two groups were similar in average age $(38.5 \pm 6.8$ years versus $41.4 \pm$ 6.9 years, $\mathrm{p}=0.12)$, mean BMI $\left(28.8 \pm 2.1 \mathrm{~kg} / \mathrm{m}^{2}\right.$ versus $\left.28.4 \pm 2.8 \mathrm{~kg} / \mathrm{m}^{2}, \mathrm{p}=0.16\right)$, and male gender $(39.0 \%$ versus $36.0 \%, \mathrm{p}=0.80)$. After three months of study protocols, 53 patients (28 in the intervention group and 25 in the control group) completed the study. Figure 1 shows the consort flow diagram of the trial. Serum levels of vitamin D increased, while insulin level and, consequently, insulin resistance (calculated by the HOMA formula) significantly decreased in the case group ( $\mathrm{p}$-value $<0.001$ for all variables) (Table 1). Although the values of these three biomarkers showed a slight increase in the control group, the changes were not statistically significant. As shown in Table 1, the levels of the changes in other markers, including adiponectin, FBS, triglycerides, and total cholesterol, were not significant in either of the study groups after completing interventions compared with before interventions. 


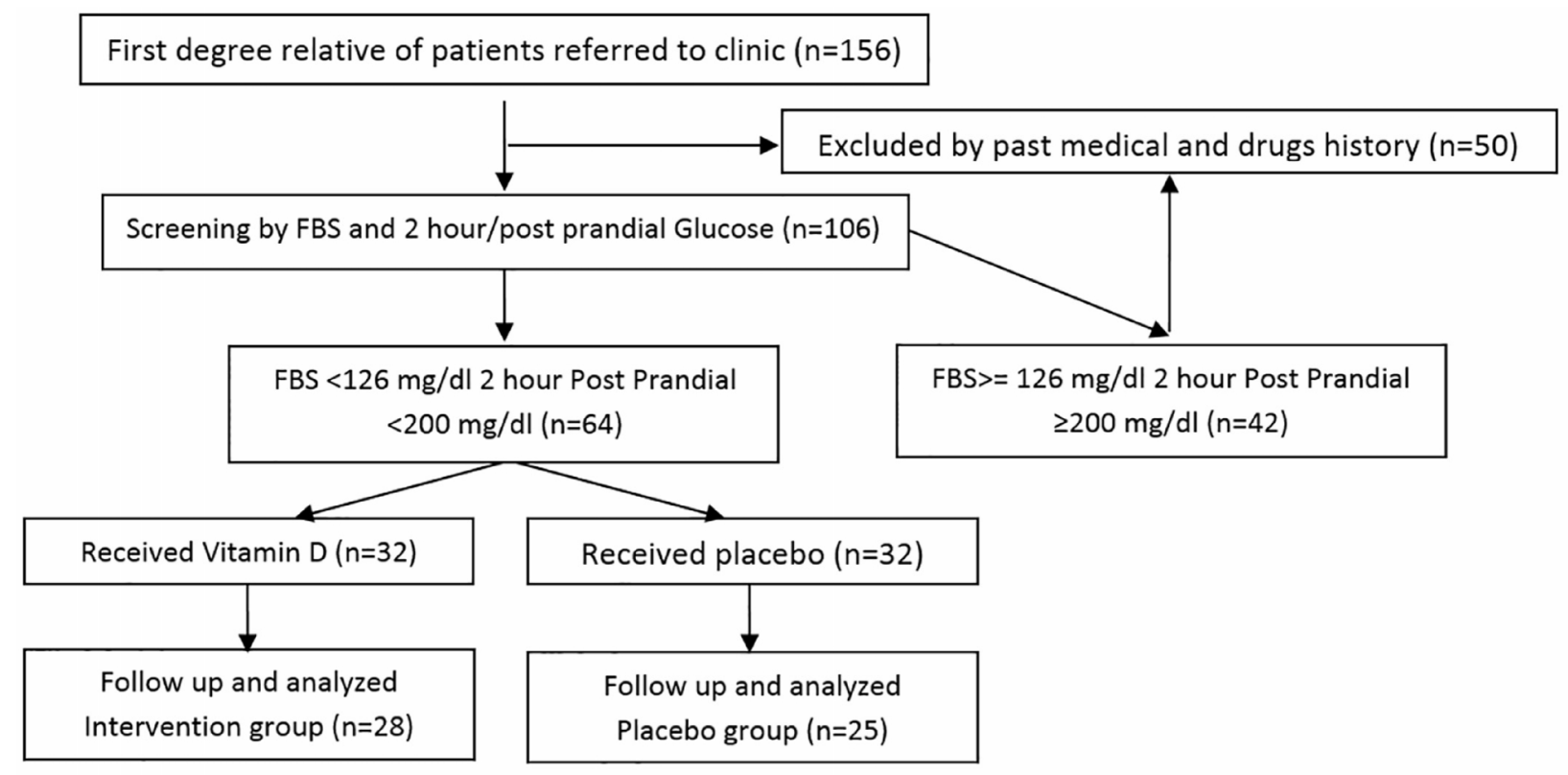

Figure 1. CONSORT flow diagram of the trial

Table 1. Comparison of test results between the two groups before and after intervention

\begin{tabular}{|c|c|c|c|c|c|}
\hline \multicolumn{2}{|l|}{ Variables } & Before Intervention & After Intervention & $p$-value ${ }^{1}$ & $p$-value ${ }^{2}$ \\
\hline \multirow[t]{2}{*}{ Vitamin D (ng/ml) } & Study group & $19.0 \pm 2.2$ & $69.0 \pm 7.5$ & $<0.001$ & \multirow[t]{2}{*}{$<0.001$} \\
\hline & Control & $23.0 \pm 1.8$ & $25.0 \pm 2.2$ & 0.28 & \\
\hline \multirow[t]{2}{*}{ Insulin $(\mu \mathrm{U} / \mathrm{ml})$} & Study group & $10.6 \pm 3.0$ & $7.1 \pm 2.9$ & $<0.001$ & \multirow[t]{2}{*}{$<0.001$} \\
\hline & Control & $6.77 \pm 2.1$ & $7.0 \pm 1.8$ & 0.11 & \\
\hline \multirow[t]{2}{*}{ Insulin Resistance } & Study group & $2.3 \pm 0.7$ & $1.5 \pm 0.5$ & $<0.001$ & \multirow[t]{2}{*}{$<0.001$} \\
\hline & Control & $1.6 \pm 0.2$ & $1.9 \pm 0.3$ & 0.24 & \\
\hline \multirow[t]{2}{*}{ Adiponectin (ng/ml) } & Study group & $4.6 \pm 4.2$ & $4.2 \pm 3.7$ & 0.86 & \multirow[t]{2}{*}{0.36} \\
\hline & Control & $5.1 \pm 4.3$ & $3.2 \pm 2.8$ & 0.12 & \\
\hline \multirow[t]{2}{*}{ Cholesterol (mg/dl) } & Study group & $192 \pm 28$ & $192 \pm 39$ & 0.97 & \multirow[t]{2}{*}{0.86} \\
\hline & Control & $196 \pm 32$ & $199 \pm 30$ & 0.66 & \\
\hline \multirow[t]{2}{*}{ Triglyceride $(\mathrm{mg} / \mathrm{dl})$} & Study group & $177 \pm 137$ & $186 \pm 128$ & 0.72 & \multirow[t]{2}{*}{0.56} \\
\hline & Control & $163 \pm 54$ & $154 \pm 38$ & 0.49 & \\
\hline \multirow[t]{2}{*}{ FBS (mg/dl) } & Study group & $94.2 \pm 9.4$ & $90.0 \pm 18.6$ & 0.92 & \multirow[t]{2}{*}{0.29} \\
\hline & Control & $97.2 \pm 11.2$ & $94.6 \pm 12.5$ & 0.17 & \\
\hline
\end{tabular}

1: $\mathrm{p}$-value within groups, 2: $\mathrm{p}$-value between groups

\section{Discussion}

Our randomized clinical trial showed significant changes in the serum levels of vitamin D and insulin as well as insulin resistance after three months by using 50,000 IU of vitamin D, however these changes were not statistically significant for the values of other serum biomarkers, including adiponectin, lipid profile, FBS, and BMI. Similar findings were found in some previous studies. In a double-blind study performed by Von Hurst et al. (11), 4000 IU/day of vitamin D given to 42 patients and placebo to 39 patients of non-diabetic Asian women for 6 months led to decrease in insulin resistance in the case group at the end of study, but without significant change in placebo group. Another study by Petchey et al. (12) on 51 patients aged $>18$ with low serum levels of vitamin D showed decrease in insulin resistance in the group who received $2000 \mathrm{IU} /$ day of cholecalcipherol for 6 months. Talaei et al. (13) indicated a decrease in insulin resistance in patients who received 50,000 unit of vitamin D for 8 weeks. Also, another research conducted by Pittaset et al. (14) on 92 patients in which the case group received calcium citrate $(500 \mathrm{mg})$ in addition to vitamin D $(700 \mathrm{mg})$ daily for 3 years showed a significant reduction of insulin resistance in 
those patients. These results are in agreement with our study despite our shorter duration. In a study done by Nagpal et al. (15) on 100 men aged $>35$, the patients were divided into two groups. The case group received three doses of 120,000 IU vitamin D every two weeks, and the control group received a placebo. Insulin resistance and serum insulin level were unchanged after completion of study, which may have been due to the short duration of the study compared to ours. In research conducted by Gannageet et al. (16) on 381 university students, a direct association was observed between serum levels of vitamin D and adiponectin. Similar results were found in Liu et al.'s (17) study, which was performed on 808 non-diabetic patients. The results of these studies are in disagreement with our study, probably due to different study design and smaller sample sizes. In Von Hurst's (10) and Pittas' (12) studies, there were no significant changes in mean serum lipids. These findings resembled those of our study. In addition, Pittas' (12) research showed significant changes in FBS level, which may be described by the long duration of the trial (3 years). In other study performed by Afkhami-Ardekani et al. (18) on 84 patients with type 2 diabetes, it was indicated that receiving $1000 \mathrm{mg}$ of vitamin $\mathrm{C}$ daily for six weeks may reduce blood glucose and lipids.

\section{Conclusions}

Based on our results, we can conclude that vitamin D may decrease serum insulin and insulin resistance in patients at risk for diabetes. But to evaluate the effects of vitamin D on serum adiponectin, more clinical trials are needed. In our study, we observed significant changes in serum levels of vitamin D and insulin as well as insulin resistance after three months use of 50,000 IU of vitamin D, but these changes were not statistically significant for serum adiponectin, lipids, FBS, and BMI. More study is required before we could recommend the consumption of vitamin $\mathrm{D}$ to these subjects for prevention of diabetes in persons at risk for type 2 diabetes.

\section{Acknowledgments:}

This paper was extracted from an Internal Medicine residency thesis $(\mathrm{P} / 17 / 1 / 50970)$ at Shahid Sadoughi University of Medical Sciences in Yazd, Iran. The authors appreciate the assistance and cooperation provided by the staff members in the Internal Medicine Department at Shahid Sadoughi Hospital, and we sincerely appreciate all of the patients who participated in the study. Special thanks are given to all investigators of Endocrine Ward of Shahid Sadoughi Hospital and Yazd Diabetes Research Center.

\section{Trial Registration:}

The trial was registered at the Iranian Registry of Clinical Trials (http://www.irct.ir) with the IRCT ID: 201105176430 N1.

\section{Funding:}

The authors received no financial support for the research or publication of this article.

\section{Conflict of Interest:}

There is no conflict of interest to be declared.

\section{Authors' contributions:}

All authors contributed to this project and article equally. All authors read and approved the final manuscript.

\section{References:}

1) American Diabetes Association. Diagnosis and classification of diabetes mellitus. Diabetes Care. 2011;34: Suppl 1: S62-9. doi: 10.2337/dc11-S062.

2) Wild S, Roglic G, Green A, Sicree R, King H. Global prevalence of diabetes. Diabetes Care. 2004; 27: 1047- 53. doi: 10.2337/diacare.27.5.1047, PMID: 15111519.

3) Afkhami-Ardekani M, Vahidi S, Vahidi A, Ahmadieh MH. Assessment of Epidemiological Indices of Diabetes Mellitus in Urban Population Of Yazd province aged $\geqslant 30$ in 1998. Journal of Yazd Shahid Sadoughi University of Medical Sciences. 2001; 1: 22-7.

4) Zeitz U, Weber k, Soegiarto DW, Wolf E, Balling R, Erben RG. Impaired insulin secretory capacity in mice looking a functional vitamin D receptor. FASEB J. 2003; 17(3): 509-11. PMID: 12551842.

5) Ford E, Ajani UA, McGuire LC, Liu S. Concentration of serum vitamin D and the metabolic syndrome Among U.S Adult. Diabetes care. 2005; 28(5): 1228-30. doi: 10.2337/diacare.28.5.1228, PMID: 15855599.

6) Mantzoros CS, Li T, Manson JE, Meigs JB, Hu FB. Circulating adiponectin levels are associated with better glycemic control, more favorable lipid profile, and reduced inflammation in women with type 2 diabetes. J Clin Endocrinol Metab. 2005; 90(8): 4542-8. doi: 10.1210/jc.2005-0372, PMID: 15914524. 
7) Kadowaki T, Yamauchi T, Kubota N, Hara K, Ueki K, Tobe K. Adiponectin and Adiponectin receptors in insulin resistance, diabetes, and metabolic syndrome. J Clin Invest. 2006; 116(7): 1784-92. doi: 10.1172/JCI29126, PMID: 16823476, PMCID: PMC1483172.

8) Yamauchi T, Kamon J, Waki H, Terauchi Y, Kubota N, Hara K, et al. The fat derived hormone adiponectin reverses insulin resistance associated with both lipoatrophy and obesity. Nat Med. 2001; 7(8): 941-6. doi: 10.1038/90984, PMID: 11479627.

9) Li s, Shin JJ, Ding El, Van Dam RM. Adiponectin levels and risk of Type 2 diabetes: A systematic review and meta-analysis. JAMA. 2009; 302(2): 179-88. doi: 100.1001/jama.2009.976, PMID: 19584347.

10) Soheilykhah S, Mohammadi M, Mojibian M, Rahimi-Saghand S, Rashidi M, Hadinedoushan, $H$, et al. Maternal serum adiponectin concentration in gestational diabetes. Gynecol Endocrinol. 2009; 25(9): 593 -6. doi: 10.1080/09513590902972109, PMID: 19626510.

11) Von Hurst PR, stonehouse W, Matthys C, conlon C, Kruger MC, Coad J. Study protocol-Metabolic syndrome, vitamin D and bone status. In south Asian women living in Auckland, New Zealand: a randomized placebo-controlled, double-blind vitamin D intervention. BMC Public health. 2008; 8: 267-74. doi: 10.1186/1471-2458-8-267, PMID: 18667086.

12) Petchey WG, Hickman IJ, Duncan E, Prins JB, Hawley CM, Johnson DW, et al. The role of 25-Hydrody vitamin $\mathrm{D}$ deficiency in promoting insulin resistance and inflammation in patients with cronic kidney disease: a randomized controlled trial. BMC nephrology. 2009; 10: 41-6. doi: 10.1186/1471-2369-10-41, PMID: 20003316.

13) Talaei A, Mohamadi M, Adgi Z. The effect of vitamin D on insulin resistance in patients with type 2 diabetes. Diabetol Metab Syndr. 2013; 5(8): 1-5. doi: 10.1186/1758-5996-5-8, PMID: 23443033.

14) Pittas AG, Harris SS, Stark pc. Dawson Hoghes B. the effect of calcium and vitamin D supplement on Blood Glucose Marker of inflammation in nondiabetic Adult. Diabetes care. 2007; 30(4): 980-6. PMID: 17277040.

15) Nagpal J, Pande JN, Bhartia A. A double-blind, randomized, placebo-controlled trial of the short-term effect of vitamin D3 supplementation on insulin sensitivity in apparently healthy, middle-aged, centrally obese men. Diabetic Medicine. 2009; 26(1): 19-27. doi: 10.1111/j.1464-5491.2008.02636.x, PMID: 19125756.

16) Gannage-Yared MH, chedid R, khalifes, sohbif, Halady G. vitamin D in relation to metabolic risk factor, insulin sensitivity and adiponectin in a young middle- Eastern population. Eur J Endocrinol. 2009; 160(6): 965-71. doi: 10.1530/EJE-08-0952, PMID: 19289535.

17) Liu E, Meigs JB, Pittas AG, McKeown NM, Economos CD, Booth SL, et al. Plasma 25-Hydroxy vitamin $\mathrm{D}$ is associated with markers of the insulin resistant phenotype in nondiabetic adults. J Nutr. 2009; 139(2): 329-34. doi: 10.3945/jn.108.093831, PMID: 19106328.

18) Afkhami-Ardekani M, Shojaoddiny-Ardekani A. Effect of vitamin C on blood glucose, serum lipids \& serum insulin in type 2 diabetes patients. Indian J Med Res. 2007; 126(5): 471-4. PMID: 18160753. 